\title{
Perception of Dental Professionals towards Biostatistics
}

\author{
Manu Batra, ${ }^{1}$ Mudit Gupta, ${ }^{2}$ Subha Soumya Dany, ${ }^{3}$ and Prashant Rajput ${ }^{3}$ \\ ${ }^{1}$ Department of Public Health Dentistry, Teerthanker Mahaveer Dental College and Research Centre, Moradabad, India \\ ${ }^{2}$ Department of Oral Medicine \& Radiology, Uttaranchal Dental \& Medical Research Institute, Dehradun, Uttarakhand, India \\ ${ }^{3}$ Department of Public Health Dentistry, Kothiwal Dental College and Research Centre, Moradabad, India
}

Correspondence should be addressed to Prashant Rajput; dr.prashantrajput@gmail.com

Received 29 May 2014; Revised 26 July 2014; Accepted 4 August 2014; Published 29 October 2014

Academic Editor: Luis-Alfonso Arráez-Aybar

Copyright (C) 2014 Manu Batra et al. This is an open access article distributed under the Creative Commons Attribution License, which permits unrestricted use, distribution, and reproduction in any medium, provided the original work is properly cited.

\begin{abstract}
Biostatistics is becoming an integral part of dental sciences. Awareness regarding the subject is not thoroughly assessed in the field of dentistry. So the study was conducted to assess dental professionals' knowledge, attitude, and perception toward biostatistics at an academic dental institution. An anonymous cross-sectional questionnaire survey was conducted among all the faculty and postgraduate students of two dental colleges in Moradabad, Uttar Pradesh. The responses were assessed on 5-point likert scale. The survey response rate was $73.71 \%$. Two-thirds of respondents believed biostatistics to be a difficult subject and at the same time half of them did not consider it to be more difficult than other subjects in dentistry. Females were less competent than males in applying biostatistical skills which was found to be statistically significant. Results suggested that dentists with research or academics as an adjunct to their clinical practice had better command over the subject. The current study shows that there is lack of command over the subject of biostatistics among dental professionals although they were aware of its importance in dentistry. There is a need of changing the training pattern of biostatistics for dental professionals which would make them confident enough to apply biostatistics in their clinical practice.
\end{abstract}

\section{Introduction}

It has become a tough task to remain updated with the dental literature as the number of dental publications has increased several folds [1]. Nowadays it has become routine work for the clinician and academicians to review articles that might have an impact on patient care, as well as articles describing changes in the philosophy of dental health care delivery and new vistas in dental research and education.

Most of the articles are accompanied by statistics. Presumably, the statistical analysis is presented by the authors to either validate or question their findings or conclusions of particular investigations or the assertions they have made in these articles.

Statistics have become an important tool or instrument in dental research. As such, when they are used judiciously and appropriately, they can shed additional light and clarity upon subjects under study. On the other hand, any tool or instrument can be misused. This can result in confusion and validation because the results or conclusions of the studies are without merit. In these instances, statistics have been used, as we have heard, "as a drunken man uses a lamppost-for support rather than illumination."

Articles in dental publications frequently include both descriptive and inferential statistics. To a great extent, authors (and editors) of dental publications rely upon professional statisticians who are experts in the field and have more than just a casual familiarity with dentistry. There is a need to figure out the associated dilemmas in concluding the statistical data. The proper use and understanding of statistics are necessary to differentiate between the "gold" and the "dross" [1].

A study of doctors' knowledge of these statistical expressions has previously been published [2]. The authors of this study concluded that the statistical knowledge of most doctors is so limited that they cannot be expected to draw the right conclusions from statistical analysis. Dentists' need for a basic statistical knowledge to a great extent is similar to doctors' [3]. 
Statistical knowledge can lead to the attitude of dental professionals towards the subject, but as a whole it depends on their perception about the same. So the objective of this survey was to evaluate the knowledge, attitude, and perception of dental professionals towards the biostatistics as it will further help in improving the teaching methods of the subject.

\section{Subjects and Methods}

An anonymous cross-sectional questionnaire based survey was conducted in two dental colleges of Moradabad, India, namely, Kothiwal Dental College and Research Centre and Teerthanker Mahaveer Dental College. All the faculty members and postgraduate students were considered eligible for this survey. For this a list of all the faculty members and postgraduate students was made along with details of their telephone numbers and e-mail addresses. Questionnaire was administered to each of the eligible members in person by the researcher. A week time was given to all the participants to fill up the questionnaire and in between reminders were sent either by telephonic conversation or by e-mail after which they were collected by the researcher only. Questions using 5-point Likert scales which were adapted from validated existing surveys that addressed medical clinicians' attitudes toward biostatistics were used [4-6]. Questions from the validated questionnaire [6] were taken directly with slight modifications being made to match it for the dental professionals. Questionnaire (Table 1) consisted of 18 questions pertaining to their knowledge about biostatistics. Demographic data were collected on sex, department, academic position, and career focus. Data were primarily analysed by PSPP version 0.6.2. Associations between responses to certain questions and demographic factors were analysed with the chi-square test level of statistical significance being set as 0.05 . This study was approved by the Ethical Committee of Kothiwal Dental College and Research Centre and consent to conduct the study was obtained from the Heads of both of the abovementioned institutions.

\section{Results}

The survey response rate was $73.71 \%$ (258/350). Response rates differed by academic position, with a significantly lower response rate among teaching faculty $(54.73 \%$ versus $87.62 \%$ among postgraduate students; $P<0.001)$. One hundred and forty-two (78.02\%) of 182 eligible male participants and one hundred and sixteen (69.05\%) of 168 eligible female participants responded. Out of total respondents faculty members were $81(31.4 \%)$ and 177 (68.6\%) were postgraduate students. Most of the study participants (57.7\%) focused on academic clinical careers followed by research work (Table 2).

Responses to each of the individual survey questions are presented in Table 3. Biostatistics was believed to be a difficult subject by $64.3 \%$ respondents, and also $53.5 \%$ subjects disagreed that it is more difficult than other subjects in dentistry. Most of the respondents (63.2\%) believed that it would be helpful for them if the teachers/consultant biostatisticians whom they are consulting for statistical help have some knowledge of dentistry so that they could understand their needs. $69.8 \%$ respondents agreed that knowing biostatistics will benefit their career.

Only $26.0 \%$ of respondents reported that their training in biostatistics was adequate for their needs whereas $27.2 \%$ felt that their current level of training in biostatistics in dentistry is adequate and only $23.6 \%$ thought their biostatistics coursework had been taught effectively. A total of $30.2 \%$ of respondents agreed that they could identify when correct statistical methods had been applied in a study and $31.3 \%$ of respondents believed they could design their own research projects with confidence, and $17.5 \%$ respondents were confident that they can conduct their own statistical analyses with confidence.

Around $71.2 \%$ of respondents agreed that biostatistics should be an integral part of research and the same proportion of respondents feels that it is a necessary skill for research purposes. The majority of respondents (71.3\%) felt that knowledge of biostatistics is necessary while evaluating dental literature.

More female respondents $(70.7 \%)$ in comparison to male respondents $(56.3 \%)$ felt that biostatistics was a tough subject $(P=0.03)$ and very few female respondents $(13.8 \%)$ were confident that they could apply statistical analysis of their own; in comparison to this, $20.4 \%$ male respondents were confident that they could conduct their own statistical analysis $(P=0.01)$.

There was no statistical difference in their agreement on biostatistics being a difficult subject $(P=0.1)$ when comparison was made between different academic positions whereas there was a highly significant difference among the proportion of staff $(39.5 \%)$ in comparison to PG students (27.1\%) regarding the confidence of designing their own research projects $(P<0.001)$. More of staff respondents (29.6\%) were confident that they can apply statistical analysis on their own in comparison to $13.0 \%$ PG students $(P<$ 0.001).

Career focus affected the response of the questions as there were highly statistically significant differences among the clinical academic respondents, clinical nonacademic respondents, and research respondents. There were very few respondents who had other career focuses which are not considered here. Apart from research respondents the rest of respondents felt that biostatistics was a tough subject $(P<$ $0.001)$. Research respondents $(48.3 \%)$ and clinical academic respondents $(29.1 \%)$ were confident of designing their own study in comparison to clinical nonacademic respondents (17.8\%) agreeing for the same. Research respondents (41.4\%) were much more confident in conducting their own statistical analysis in comparison to other respondents $(P=0.05)$ (Table 4).

\section{Discussion}

The results of our study suggest that though more than half of the respondents understand the importance of the subject and also believe that knowing the subject will be beneficial for their career along this the same amount of respondents feels that biostatistics is a difficult subject when 
TABLE 1: Questionnaire to assess perceptions towards biostatistics.

\section{General information}

Gender:

Department:

Academic position:

Career focus: Clinical, nonacademic

$\square$ Clinical, academic

\begin{tabular}{lllll}
$\square$ & Research & $\square$ & Others & $\square$ \\
$\begin{array}{l}\text { Strongly } \\
\text { disagree }\end{array}$ & Disagree & Neutral & Agree & $\begin{array}{c}\text { Strongly } \\
\text { agree }\end{array}$ \\
\hline
\end{tabular}

General perceptions

Biostatistics is a difficult subject

Biostatistics is more difficult than any other subject in dental training

Biostatistics would be more helpful for teachers and consultants if

they understood dentistry

Within the dental field, biostatisticians have high status

It would benefit my career to better understand biostatistics

My training in biostatistics is adequate for my needs

Perceptions of knowledge and training

The current level of training in biostatistics in dentistry is adequate

My previous biostatistics coursework was taught effectively

I am able to tell when the correct statistical method has been applied in my study

I am able to design my own research projects with confidence

I am able to conduct my own statistical analyses with confidence

\section{Perceptions of biostatistics and research}

Biostatistics should be an integral part of most research

Biostatistics is a necessary skill for a clinician involved in research

Biostatistics is a necessary skill for a clinician not involved in research

Biostatisticians are not necessary for most research

Perceptions of biostatisticians and evidence based dentistry

Biostatistics is an important part of evidence based dentistry

Knowledge of biostatistics is necessary when evaluating dental

literature

Evidence based dentistry is important for clinical practice

placed next to other disciplines of dentistry; it is relegated to a supporting role. This indicates that teaching of biostatistics as a separate entity is unlikely to change the scenario. So more integrated approaches that demonstrate how biostatistics can affect patient care decisions, as suggested in other studies, may be more effective $[7,8]$, which will revive the importance of biostatistics in clinical decision making, which requires both knowledge of biological processes and interpretation of research reports [9]. In addition, the faculty who are teaching statistics in the workshops and CDE programs mostly have 
TABLE 2: Distribution of survey respondents.

\begin{tabular}{|c|c|}
\hline Demographic & Number (\%) of respondents \\
\hline \multicolumn{2}{|l|}{ Gender } \\
\hline Male & $142(55.04 \%)$ \\
\hline Female & $116(44.96 \%)$ \\
\hline \multicolumn{2}{|l|}{ Academic position } \\
\hline Staff & $81(31.4 \%)$ \\
\hline PG students & $177(68.6 \%)$ \\
\hline \multicolumn{2}{|l|}{ Career focus } \\
\hline Clinical, academic & $149(57.7 \%)$ \\
\hline Clinical, nonacademic & $45(17.5 \%)$ \\
\hline Research & $58(22.5 \%)$ \\
\hline Others & $6(2.3 \%)$ \\
\hline \multicolumn{2}{|l|}{ Department } \\
\hline Conservative and endodontics & $32(12.4 \%)$ \\
\hline Oral medicine and radiology & $28(10.8 \%)$ \\
\hline Oral pathology and microbiology & $27(10.5 \%)$ \\
\hline Orthodontics & $30(11.6 \%)$ \\
\hline Oral and maxillofacial surgery & $25(9.78 \%)$ \\
\hline Pedodontics & $26(10.1 \%)$ \\
\hline Periodontics & $29(11.2 \%)$ \\
\hline Public health dentistry & $27(10.5 \%)$ \\
\hline Prosthodontics & $34(13.2 \%)$ \\
\hline
\end{tabular}

*Some percentages do not total 100 because of rounding.

background of pure statistics and do not have the training of teaching methods of conveying statistical concepts to the dental professionals [10].

The study showed that a very small proportion of respondents were confident enough in designing their own research projects and performing statistical analysis. Our results were in agreement with Wulff et al. [2] who also concluded that statistical knowledge of doctors was unsatisfactory when it came to biostatistics. Altman and Bland [11] also highlighted the same inference. There was statistical difference by gender while considering the application of statistical tests: males were more confident than females. Studies on math performance and sex differences demonstrate that men perform better in mathematics as compared to females [12] which can elucidate the results of our study. Career focus and academic position also affected the responses of the above discussed question. The respondents who had research, or clinical along with academic career, focus were much more confident about the application of statistical tests than respondents who had clinical nonacademic career focus. Former group were more updated as they are actively encountering biostatistics in their research and academic sessions with their students quite frequently. Regarding academic position, it is quite obvious that with greater experience the faculty over scores postgraduate students in having confidence over subject.

Respondents' evaluation of biostatistics as an important element of evidence based dentistry suggested that EBD may represent an ideal vehicle for improved teaching of biostatistics. Unfortunately, many biostatisticians appear relatively unaware of the EBD movement and do not use the successful
EBD integration techniques in their teaching. Similarly, EBD has not fully embraced the teaching of statistical methods, preferring to focus instead on epidemiological principles [13, 14].

Possible solutions to the limitations in teaching biostatistics identified by our respondents can be incorporation of problem based learning into biostatistics course which can be quite helpful. There should be a student-centred approach, substantial student involvement/engagement, and heavy emphasis on application [15]. For dental students encountering statistics for the first time, with little prior knowledge, it is important that they encounter it in the context that they will be using it during their subsequent research careers. Need of the hour is to move from didactic learning towards more problem-oriented and practical approach, that is, problem based learning.

Our study results could be affected by response bias as the demographic data was not available for nonrespondents. Another limitation is that the survey has been limited to a single private dental institution so it cannot be generalized as there would be variations in responses of government institutions. This is the first study representing the perceptions of dental professionals towards biostatistics. Further research is needed to identify effective methods that will transform their perceptions towards the subject.

\section{Conclusion}

The current study shows that there is lack of command over the subject of biostatistics among dental professionals 
TABLE 3: Survey responses of dentists towards biostatistics.

\begin{tabular}{|c|c|c|c|c|c|}
\hline \multirow[b]{2}{*}{ Question } & \multicolumn{5}{|c|}{ Number (\%) } \\
\hline & $\begin{array}{l}\text { Strongly } \\
\text { disagree }\end{array}$ & Disagree & Neutral & Agree & $\begin{array}{l}\text { Strongly } \\
\text { agree }\end{array}$ \\
\hline \multicolumn{6}{|c|}{ General perceptions } \\
\hline Biostatistics is a difficult subject & $16(6.2)$ & $58(22.5)$ & $18(7.0)$ & $140(54.2)$ & $26(10.1)$ \\
\hline Biostatistics is more difficult than any other subject in dental training & $34(13.2)$ & $104(40.3)$ & $40(15.5)$ & $53(20.5)$ & $27(10.5)$ \\
\hline $\begin{array}{l}\text { Biostatistics would be more helpful for teachers and consultants if } \\
\text { they understood dentistry }\end{array}$ & $17(6.6)$ & $13(5.0)$ & $65(25.2)$ & $119(46 . f 1)$ & $44(17.1)$ \\
\hline Within the dental field, biostatisticians have high status & $17(6.6)$ & $31(12.0)$ & $92(35.7)$ & $103(39.9)$ & $15(5.8)$ \\
\hline It would benefit my career to better understand biostatistics & $5(1.9)$ & $16(6.2)$ & $57(22.1)$ & $138(53.5)$ & $42(16.3)$ \\
\hline \multicolumn{6}{|c|}{ Perceptions of knowledge and training } \\
\hline My training in biostatistics is adequate for my needs & $13(5.1)$ & $101(39.1)$ & $77(29.8)$ & $62(24.1)$ & $5(1.9)$ \\
\hline The current level of training in biostatistics in dentistry is adequate & $33(12.8)$ & $102(39.5)$ & $53(20.5)$ & $69(26.8)$ & $1(0.4)$ \\
\hline My previous biostatistics coursework was taught effectively & $11(4.3)$ & $105(40.7)$ & $81(31.4)$ & $58(22.5)$ & $3(1.1)$ \\
\hline $\begin{array}{l}\text { I am able to tell when the correct statistical method has been applied } \\
\text { in my study }\end{array}$ & $13(5.1)$ & $94(36.4)$ & $73(28.3)$ & $74(28.7)$ & $4(1.5)$ \\
\hline I am able to design my own research projects with confidence & $20(7.8)$ & $95(36.8)$ & $62(24.1)$ & $78(30.2)$ & $3(1.1)$ \\
\hline I am able to conduct my own statistical analyses with confidence & $16(6.2)$ & $119(46.1)$ & $78(30.2)$ & $43(16.7)$ & $2(0.8)$ \\
\hline \multicolumn{6}{|c|}{ Perceptions of biostatistics and research } \\
\hline Biostatistics should be an integral part of most research & $3(1.1)$ & $16(6.2)$ & $58(22.5)$ & $124(48.1)$ & $57(22.1)$ \\
\hline Biostatistics is a necessary skill for a clinician involved in research & $4(1.6)$ & $17(6.6)$ & $53(20.5)$ & $119(46.1)$ & $65(25.2)$ \\
\hline Biostatistics is a necessary skill for a clinician not involved in research & $13(5.1)$ & $95(36.8)$ & $104(40.3)$ & $41(15.9)$ & $5(1.9)$ \\
\hline Biostatisticians are not necessary for most research & $62(24.1)$ & $104(40.3)$ & $57(22.1)$ & $31(12.0)$ & $4(1.5)$ \\
\hline \multicolumn{6}{|c|}{ Perceptions of biostatisticians and evidence based dentistry } \\
\hline Biostatistics is an important part of evidence based dentistry & $13(5.1)$ & $16(6.2)$ & $32(12.4)$ & $140(54.2)$ & $57(22.1)$ \\
\hline $\begin{array}{l}\text { Knowledge of biostatistics is necessary when evaluating dental } \\
\text { literature }\end{array}$ & $5(1.9)$ & $20(7.8)$ & $40(15.5)$ & $135(52.3)$ & $58(22.5)$ \\
\hline Evidence based dentistry is important for clinical practice & $11(4.3)$ & $14(5.4)$ & $37(14.3)$ & $141(54.8)$ & $55(21.2)$ \\
\hline
\end{tabular}

${ }^{*}$ Some percentages do not total 100 because of rounding.

TABLE 4: Analysis of perception of knowledge by gender, career focus, and academic position.

\begin{tabular}{|c|c|c|c|c|c|c|c|}
\hline & & \multicolumn{2}{|c|}{$\begin{array}{c}\text { Biostatistics is a difficult } \\
\text { subject }\end{array}$} & \multicolumn{2}{|c|}{$\begin{array}{l}\text { I am able to } \\
\text { design my own } \\
\text { research projects } \\
\text { with confidence }\end{array}$} & \multicolumn{2}{|c|}{$\begin{array}{c}\text { I am able to conduct } \\
\text { my own statistical } \\
\text { analyses with } \\
\text { confidence }\end{array}$} \\
\hline & & & $P$ value & & $P$ value & & $P$ value \\
\hline \multirow{2}{*}{ Gender } & Male & $80(56.3)$ & \multirow{2}{*}{0.03} & $53(37.3)$ & \multirow{2}{*}{0.06} & $29(20.4)$ & \multirow{2}{*}{0.01} \\
\hline & Female & $82(70.7)$ & & $22(18.9)$ & & $16(13.8)$ & \\
\hline \multirow{2}{*}{ Academic position } & Staff & $46(56.8)$ & \multirow{2}{*}{0.1} & $32(39.5)$ & \multirow{2}{*}{$<0.001$} & $24(29.6)$ & \multirow{2}{*}{$<0.001$} \\
\hline & PG students & $109(61.6)$ & & $48(27.1)$ & & $23(13.0)$ & \\
\hline \multirow{3}{*}{ Career focus } & Clinical academic & $114(76.5)$ & \multirow{3}{*}{$<0.001$} & $44(29.5)$ & & $21(14.1)$ & \multirow{3}{*}{0.005} \\
\hline & Clinical nonacademic & $40(88.9)$ & & $8(17.8)$ & $<0.001$ & $6(13.3)$ & \\
\hline & Research & $4(6.9)$ & & $28(48.3)$ & & $24(41.4)$ & \\
\hline
\end{tabular}

\footnotetext{
${ }^{\#} P$ values based on chi-square test.
} 
although they were aware of its importance in dentistry. The fact that only $23.6 \%$ of respondents agreed or strongly agreed that their biostatistics courses were taught effectively suggests that there is a need of changing the training pattern of biostatistics for dental professionals which would make them confident enough to apply biostatistics in their clinical practice.

\section{Conflict of Interests}

The authors declare that there is no conflict of interests regarding the publication of this paper.

\section{References}

[1] Statistics in Dentistry, NYSDJ, August-September, 2007.

[2] H. R. Wulff, B. Andersen, P. Brandenhoff, and F. Guttler, "What do doctors know about statistics?" Statistics in Medicine, vol. 6, no. 1, pp. 3-10, 1987.

[3] F. Scheutz, B. Andersen, and H. R. Wulff, "What do dentists know about statistics?" Scandinavian Journal of Dental Research, vol. 96, no. 4, pp. 281-287, 1988.

[4] S. L. Wise, "The development and validation of a scale measuring attitudes toward statistics," Educational and Psychological Measurement, vol. 45, pp. 401-405, 1985.

[5] C. Schau, J. Stevens, T. L. Dauphinee, and A. del Vecchio, "The development and validation of the survey of attitudes toward Statistics," Educational and Psychological Measurement, vol. 55, pp. 868-875, 1995.

[6] C. P. West and R. D. Ficalora, "Clinician attitudes toward biostatistics," Mayo Clinic Proceedings, vol. 82, no. 8, pp. 939943, 2007.

[7] J. Astin, T. Jenkins, and L. Moore, "Medical students' perspective on the teaching of medical statistics in the undergraduate medical curriculum," Statistics in Medicine, vol. 21, no. 7, pp. 1003-1006, 2002.

[8] P. R. Marantz, W. Burton, and P. Steiner-Grossman, "Using the case-discussion method to teach epidemiology and biostatistics," Academic Medicine, vol. 78, no. 4, pp. 365-371, 2003.

[9] D. R. Appleton, "What statistics should we teach medical undergraduates and graduates?" Statistics in Medicine, vol. 9, no. 9, pp. 1013-1029, 1990.

[10] N. Khan and Y. Mumtaz, "Attitude of teaching faculty towards statistics at a medical university in Karachi, Pakistan," Journal of Ayub Medical College Abbottabad, vol. 21, no. 3, pp. 166-171, 2009.

[11] D. G. Altman and J. M. Bland, "Improving doctors understanding of statistics," Journal of the Royal Statistical Society A, vol. 154, pp. 223-267, 1991.

[12] A. Feingold, "Cognitive gender differences are disappearing," American Psychologist, vol. 43, no. 2, pp. 95-103, 1988.

[13] R. W. Morris, "Does EBM offer the best opportunity yet for teaching medical statistics?" Statistics in Medicine, vol. 21, pp. 969-977, 2002.

[14] S. I. Shah, "Viewpoint: pancakes and medical statistics," Academic Medicine, vol. 80, no. 5, pp. 452-454, 2005.

[15] A. S. Nowacki, "Using the 4MAT framework to design a problem-based learning biostatistics course," Journal of Statistics Education, vol. 19, no. 3, pp. 1-24, 2011. 


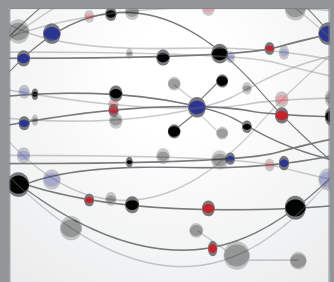

The Scientific World Journal
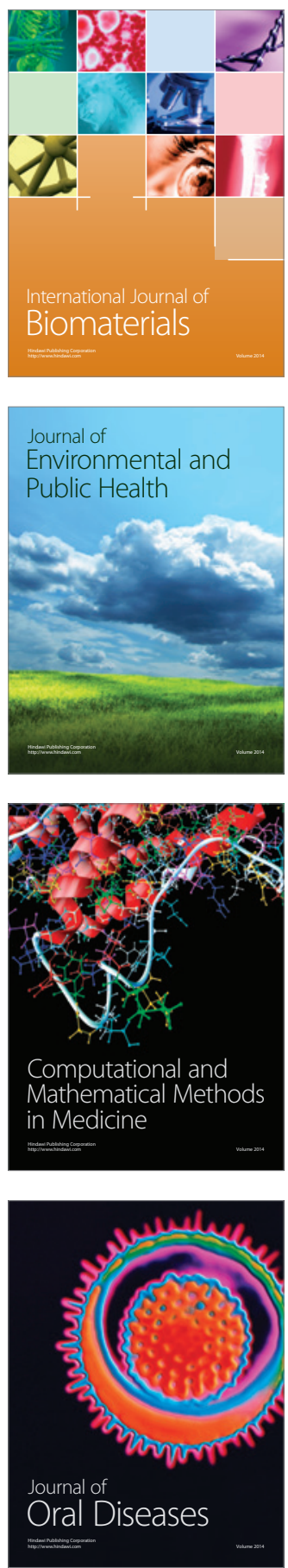
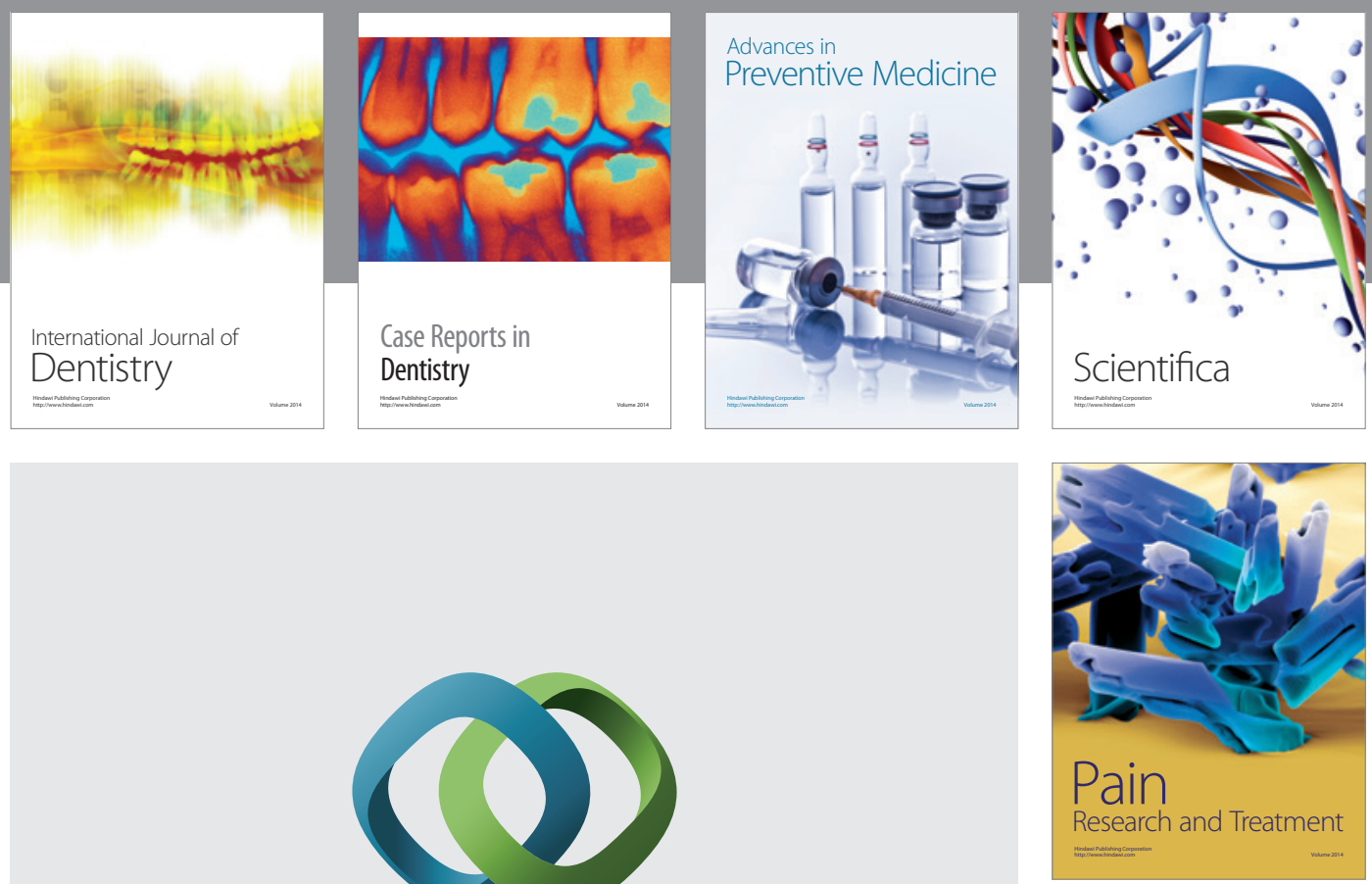

\section{Hindawi}

Submit your manuscripts at

http://www.hindawi.com
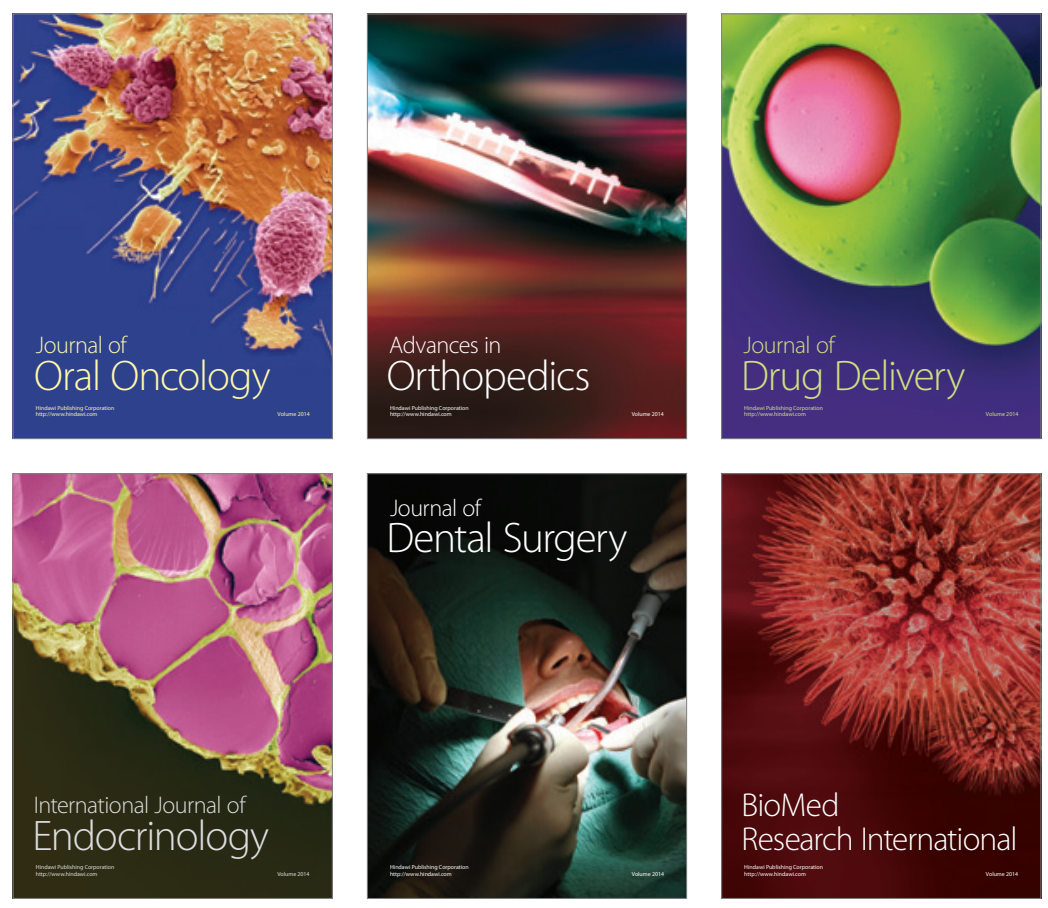

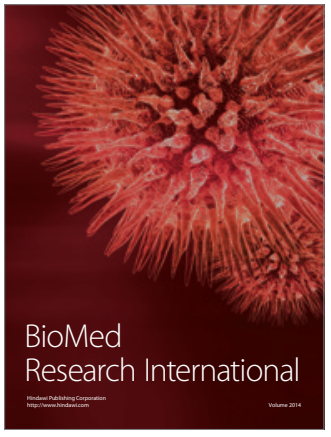

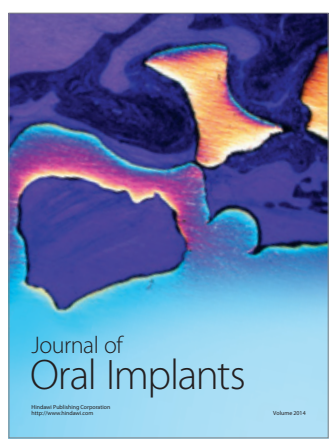
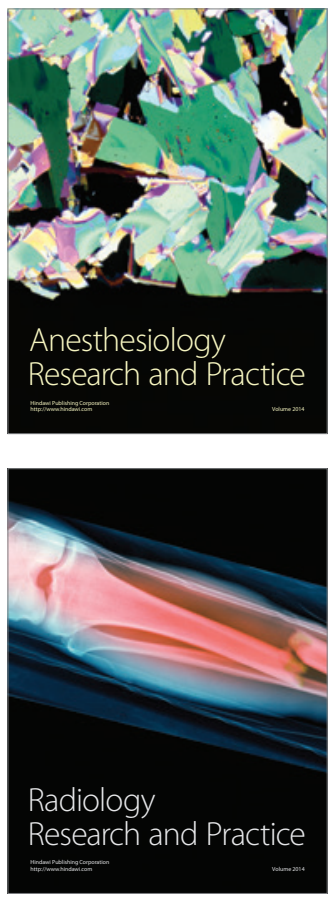